\title{
Introdução ao estudo da sociedade industrial avançada em Herbert Marcuse ${ }^{1}$ Introduction to the advanced industrial society study in Herbert Marcuse
}

\author{
RENÊ IVO DA SILVA LIMA²
}

Resumo: O artigo tem como objetivo apresentar, segundo o pensamento de Herbert Marcuse, algumas das relações sociais que caracterizam a sociedade industrial avançada. Como referência principal, utilizamos a introdução do livro $\mathrm{O}$ homem unidimensional, intitulada de "A paralisia da crítica: uma sociedade sem oposição"; o primeiro capítulo, do mesmo livro, intitulado de "As novas formas de controle" e o segundo capítulo, da mesma obra, intitulado de "O fechamento do universo político". O problema que esta pesquisa levanta é o seguinte: quais são algumas das relações sociais que caracterizam a sociedade industrial avançada? A conclusão a qual chegamos é que algumas das relações sociais que caracterizam a sociedade estabelecida são: o aperfeiçoamento da tecnologia, o desenvolvimento de uma superprodutividade, o fornecimento de um elevado padrão de vida e o desenvolvimento de uma racionalidade tecnológica. Essas relações sociais integram os indivíduos à ordem social existente, elas paralisam o pensamento e comportamento crítico dos membros da classe dominada e os impede de compreender e sentir a necessidade de superar a sociedade unidimensional.

Palavras-chave: Sociedade industrial avançada. Novas formas de controle. Racionalidade tecnológica. Pensamento e comportamento unidimensional.

Abstract: The article aims to present, according to the thought of Herbert Marcuse, some of the social relations that characterize advanced industrial society. As the main reference we use the introduction of the book One-Dimensional Man, titled "The Paralysis of Criticism: A Unopposed Society"; the first chapter of the same book, entitled "The New Forms of Control," and the second chapter of the same book entitled "The Closure of the Political Universe." The problem this research raises is the following: what are some of the social relations that characterize advanced industrial society? The conclusion we come to is that some of the social relations that characterize the established society are: the improvement of technology, the development of a superproductivity, the provision of a high standard of living and the development of a technological rationality. These social relations integrate individuals into the existing social order, they paralyze the thinking and critical behavior of members of the dominated class and prevent them from understanding and feeling the need to overcome one-dimensional society.

Keywords: Advanced industrial society. New forms of control. Technological rationality. Thinking and one-dimensional behavior.

\section{Introdução}

\footnotetext{
${ }^{1}$ Este artigo, com algumas alterações, constitui o primeiro capítulo da monografia "Alternativas de superação da sociedade unidimensional em Herbert Marcuse: um estudo sobre $O$ homem unidimensional", de minha autoria, sob a orientação do prof. Ms. John Karley de Sousa Aquino (IFCE).

${ }^{2}$ Mestrando em Filosofia pelo Programa de Pós-Graduação da Universidade Federal do Ceará (UFC). Bolsista CAPES. Membro do Grupo de Estudos e Pesquisas "Atualidade do pensamento de Herbert Marcuse". E-mail: reneivo@hotmail.com.
} 
“Com certeza, essa ainda é a máxima do filósofo; é ele quem analisa a situação humana. Ele sujeita a experiência ao seu julgamento crítico, e este contém um julgamento de valor - a saber, que a libertação do esforço é preferível ao esforço, e uma vida inteligente é preferível a uma vida estúpida."

(Herbert Marcuse)

A partir do século XX, a sociedade capitalista começara a passar por algumas transformações decisivas à continuidade de suas relações sociais, alguns pensadores da referida época perceberam e entenderam tais mudanças, outros nem tanto. Herbert Marcuse (1898-1979) foi um dos filósofos que não só compreendeu tais alterações, como também desenvolveu uma teoria crítica com o objetivo de denunciar e superar as novas relações sociais da sociedade estabelecida. Dessa maneira, o seu pensamento foi tanto aceito quanto recusado ${ }^{3}$ por diferentes setores da sociedade.

Críticas e elogios à parte, Marcuse prosseguiu desenvolvendo uma teoria crítica da sociedade capitalista capaz de apresentar as contradições e, ao mesmo tempo, as alternativas apropriadas para a superação do status quo e construção de uma sociedade qualitativamente melhor ${ }^{4}$. Ele compreendia que a vida humana é digna ser vivida, quer dizer, que ela pode ser e deve ser feita digna de ser vivida e que na própria sociedade capitalista existiriam as possibilidades para que todas as pessoas possam viver, viver bem e viver melhor. Assim, o seu pensamento não se limita a descrever os impasses da organização social estabelecida, mas a partir deles compreender que uma nova forma de organizar as relações sociais é possível.

Com o intuito de demonstrar como se organiza o novo estágio da sociedade capitalista e, por conseguinte, as novas formas de dominação da classe oprimida, este artigo propõe como objetivo geral apresentar, segundo o pensamento de Herbert Marcuse, algumas das relações sociais que caracterizam a sociedade industrial avançada. Dessa maneira, o problema que esta pesquisa levanta é o seguinte: quais são algumas das relações sociais que caracterizam a sociedade industrial avançada?

\footnotetext{
${ }^{3}$ Segundo Robespierre de oliveira, no seu livro O papel da filosofia na teoria crítica de Herbert Marcuse, “(...) Marcuse foi tanto elogiado quanto alvo de duras críticas. Havia aqueles que censuravam o seu marxismo, alguns o considerando como um pré-marxista, outros como um não marxista, e até como um antimarxista. Parte da esquerda, avessa às críticas de Marcuse ao 'marxismo petrificado' da tradição soviética, censurava-o por obscurecer a consciência de classe dos trabalhadores com suas teorias sobre a sociedade unidimensional, considerando-o um 'pessimista' ante o quadro geral de mobilizações da época" (OLIVEIRA, 2012, p. 15).

${ }^{4}$ Isabel Loureiro, no seu artigo Herbert Marcuse: cem anos, afirma que "Marcuse foi o único filósofo da Escola de Frankfurt que mesmo sem ter militância política em sentido estrito, sempre permaneceu um teórico da revolução. A sua obra gira desde o início em torno de um problema - a necessidade de transformação revolucionária da sociedade capitalista" (LOUREIRO, 1998, p. 157).
} 
A justificativa que nos levou a desenvolver este trabalho foi a necessidade de demonstrar a atualidade do pensamento de Marcuse no que diz respeito às transformações pelas quais a sociedade existente tem passado. A nosso ver, compreender tais alterações torna-se fundamental para entendermos o processo de construção de uma resistência eficaz frente às formas de controle perpetrados sobre a classe dominada. Entender a organização da sociedade estabelecida pode nos fazer perceber a necessidade de elaborar um modo de vida qualitativamente diferente.

Desse modo,na primeira seção do presente artigo apresentamos como se organiza a sociedade industrial avançada, isto é, sua origem, seu desenvolvimento e suas implicações sociais. Na segunda seção expomos as novas formas de controle existentes na sociedade estabelecida e, por fim, na terceira seção apresentamos o desenvolvimento da racionalidade tecnológica. Portanto, a conclusão a qual chegamos é que o desenvolvimento das relações sociais da sociedade industrial avançada integra os indivíduos à ordem social existente, elas paralisam o pensamento e comportamento crítico dos membros da classe dominada e os impede de compreender e sentir a necessidade de superar a sociedade unidimensional ${ }^{5}$.

\section{Sociedade industrial avançada}

A partir do começo do século XX, a sociedade capitalista dá início ao desenvolvimento de um "novo estágio", Marcuse denomina essa fase de "sociedade industrial avançada". Uma das principais distinções desse estágio da sociedade capitalista é a união entre produtividade e destrutividade, isto é, ao mesmo tempo em que ela produz um crescente padrão de vida, também produz exploração e destruição dos seres humanos e da natureza. De acordo com Marcuse, essa ordem social,

[...] que ganha corpo nas mais avançadas áreas da civilização industrial, combina em produtiva união as características do Estado de Bem-Estar Social (WelfareState) e do Estado de Guerra (WarfareState). Comparada com "suas precursoras", ela é, na verdade, uma "nova sociedade". (MARCUSE, 2015, p. 55).

Ela configura um novo estágio da sociedade capitalista porque conseguiu desenvolver novas relações sociais diferentes das relações sociais vigentes nos estágios anteriores dessa sociedade, assim, por exemplo, "Os pontos tradicionalmente problemáticos estão sendo eliminados ou isolados, os elementos perturbadores estão sendo dominados" (MARCUSE, 2015, p. 55). Desse modo, alguns problemas dos períodos anteriores da sociedade capitalista que pareciam ser

\footnotetext{
${ }^{5}$ Sociedade unidimensional é a sociedade estabelecida. É a sociedade que tenta integrar toda e qualquer oposição ao modo de vida existente; é a ordem social que tenta absorver toda e qualquer forma de contestação das relações sociais vigentes; é a organização social que tenta refutar toda e qualquer alternativa de construção de uma sociedade qualitativamente diferente.
} 
impossíveis de ser resolvidos, agora, com o surgimento da mais recente fase dessa civilização, tais dificuldades parecem ser solucionadas. Essa fase da sociedade parece ser capaz de apaziguar as forças sociais dissidentes, parece estar conseguindo reconciliar os interesses opostos das classes antagônicas. Para Marcuse, as principais tendências da sociedade industrial avançada são:

\begin{abstract}
concentração da economia nacional nos interesses das grandes corporações, [...] atrelamento dessa economia com um sistema mundial de alianças militares, acordos monetários, assistência técnica e esquemas de desenvolvimento; gradual assimilação dos 'colarinhos azuis' e dos 'colarinhos brancos', [...] do lazer e das aspirações em diferentes classes sociais; [...] invasão da esfera privada pela aproximação da opinião pública; abertura da intimidade aos meios de comunicação de massa (MARCUSE, 2015, p. 55).
\end{abstract}

Essas são algumas relações sociais prevalecentes na sociedade industrial avançada, mas também existem outras relações sociais fundamentais para sua perpetuação. Com a reconfiguração da sociedade capitalista surgem também novas formas e modos de organizar a vida. As relações sociais que distinguem esse novo momento são várias, mas é possível destacar algumas das mais importantes: o aperfeiçoamento cada vez maior e melhor da tecnologia ${ }^{6}$, o desenvolvimento sem precedentes da produtividade e o fornecimento de um crescente padrão de vida são alguns exemplos daquelas relações. Estas estimulam o desenvolvimento de algumas daquelas tendências referidas por Marcuse na citação anterior e criam as condições de melhorar ou tornar ainda mais difícil a vida dos seres humanos.

As relações sociais vigentes na sociedade estabelecida foram construídas por todos os homens e mulheres, mas estas relações não foram decididas autonomamente por todos os indivíduos, e, sim, por uma minoria, isto é, pela classe dominante e, dessa maneira, essas relações buscam satisfazer o interesse da classe que as impôs. Desse modo, a sociedade industrial avançada é uma forma específica de organização social, cujo objetivo é manter inalterada as relações sociais que contribuem para perpetuar o estado de coisas vigente. Este consiste em manter a classe dominante na sua posição privilegiada à custa da exploração da classe dominada.

Assim, na sociedade existente, quanto mais aumenta a produtividade maior é o lucro apropriado pela classe dominante, pois essa produtividade se expande para a maior parte da sociedade e alcança uma parcela cada vez maior da população, alargando o leque de compradores e consumidores de bens e serviços supérfluos ${ }^{7}$.

\footnotetext{
${ }^{6}$ Nesse trabalho não fazemos distinção entre "progresso técnico", "tecnologia" e "técnica". Seguimos a posição de Rafael Cordeiro Silva de que "Marcuse apenas esboçou essa distinção, mas não a levou adiante" (SILVA, 2013, p. 56).

${ }^{7}$ Supérfluos na medida em que não servem à satisfação das necessidades vitais que mantém a vida,
} 
Além disso, a produção cada vez mais intensa e variada contribui diretamente com o aprimoramento da ciência e da tecnologia, na medida em que elas organizam e direcionam seus estudos para a descoberta de métodos mais eficazes de produção, ampliação e criação de novas mercadorias.

Por outro lado, quanto mais aumenta a produtividade maior é a destruição da vida, a natureza é explorada até o esgotamento, os rótulos e embalagens da exagerada quantidade de produtos supérfluos poluem os mares, rios e lagos; sujam as ruas, avenidas e estradas; entopem os esgotos e causam inundações. Na sociedade industrial avançada, os indivíduos organizam e direcionam suas vidas única e exclusivamente para a compra e consumo de bens e serviços, na verdade, só se sentem felizes e satisfeitos se possuírem artigos. Para Marcuse,

[...] essa sociedade é irracional como um todo. Sua produtividade destrói o livre desenvolvimento das necessidades e faculdades humanas, [...] seu crescimento depende da repressão das reais possibilidades de pacificação da luta pela existência - individual, nacional e internacional. (MARCUSE, 2015, p. 31-32)

Algo semelhante parece acontecer com relação à tecnologia, organizada e direcionada para satisfazer os objetivos da classe dominante, ou seja, garantir sua posição privilegiada, o progresso técnico ajuda a reproduzir as condições sociais que mantêm inalterado o estado de coisas prevalecente. A ciência e a técnica no interior do capitalismo ajudam a produzir um padrão de vida crescente, uma existência muito mais confortável e até mesmo boa para uma quantidade cada vez maior de pessoas. $\mathrm{O}$ aperfeiçoamento técnico contribui na reprodução das relações de dominação ${ }^{8}$.

O crescente padrão de vida conforma a classe oprimida com o estado de coisas existente, o elevado padrão de conforto imposto pela sociedade industrial avançada paralisa o pensamento e comportamento revolucionário da classe trabalhadora. $\mathrm{O}$ conforto predominante reduz a necessidade da revolução socialista e parece refutar toda e qualquer alternativa de emancipação, ele cria uma sensação de que todos os problemas, contradições, podem ser resolvidos dentro dos limites do status quo. $\mathrm{O}$ conforto da vida existente atrofia a capacidade das pessoas de visualizarem uma ordem social qualitativamente diferente.

De acordo com Oliveira (2015, p. 118), “A sociedade industrial avançada oferece uma enorme quantidade de bens e mercadorias para os indivíduos, de modo que

supérfluos porque não atendem às necessidades básicas de alimentação, moradia e vestuário. Um exemplo desses produtos são os automóveis, os televisores, os aparelhos celulares, etc.

${ }^{8}$ Queremos esclarecer que Marcuse não é um tecnofóbico, isto é, tem aversão à tecnologia. O autor reconhece que a técnica pode ser um fator de emancipação. Segundo Rafael Cordeiro Silva, no seu artigo Tecnologia e progresso: dois pontos de vista da teoria crítica, "Marcuse deixa bem claro não ser simpático a posições antitecnológicas. Ele faz referência explícita à tecnologia como fator de libertação" (SILVA, 2013, p. 63). 
eles acreditem na eficácia do sistema”. O sistema se legitima por meio da sua eficiência em fornecer as mercadorias que satisfazem os indivíduos, as pessoas se sentem felizes em trocar de automóvel todos os anos; em trocar seus aparelhos celulares a cada seis meses; em trocar suas roupas de grife todos os meses. Essa é uma das maneiras pela qual a ordem social estabelecida consegue conquistar a consciência da classe dominada.

A sociedade industrial avançada usa suas capacidades intelectuais e materiais para dominar o homem e a natureza e, assim, conter todo e qualquer tipo de transformação social, usa o progresso da ciência e da tecnologia para aperfeiçoar a sua estrutura de defesa. Essa estrutura, cuja expressão maior se encontra na construção do aparato bélico, está preparada para destruir qualquer forma de oposição ao establishment. Segundo Isabel Loureiro, o capitalismo avançado é uma sociedade "em que todo e qualquer tipo de oposição se encontra integrado" (LOUREIRO, 2005, p. 13).

Dessa maneira, a sociedade de capitalismo avançado, se quiser perpetuar-se tem de necessariamente integrar os indivíduos ao modo de vida existente, para que isso aconteça, ela precisa desenvolver meios capazes de mobilizar as pessoas, precisa fazer com que os seres humanos queiram jogar o seu jogo. Para mobilizar mais facilmente as pessoas para jogar o seu jogo, a ordem social estabelecida cria inimigos que ameaçam destruir a regularidade da organização social existente. Esses inimigos parecem tornar-se um estímulo para fortalecer a coesão e perpetuação da ordem social existente.

Com medo de perder os benefícios conferidos pela sociedade prevalecente, as pessoas rejeitam toda e qualquer tendência capaz de colocar em perigo sua vida confortável, para combater o inimigo os indivíduos aceitam trabalhar na produção dos meios de destruição: na produção bélica. O inimigo enfrenta o ódio dos indivíduos, neles foram inculcados interesses particulares que não fazem parte de suas próprias aspirações e que não podem ser alcançados sem a sua ajuda, esses interesses são a manutenção do ganho de lucro, a manutenção da posição de dominação da classe opressora, etc. A sociedade industrial avançada parece derrotar as alternativas que ameaçam iniciar a ruptura do status quo. Para Aquino,

[...] a sociedade industrial avançada é uma sociedade que tende rapidamente a tornar-se uma sociedade da administração total, sem espaço para posições críticas ao establishment e que exacerba a positividade e cancela (ou pretende cancelar) a negatividade no interior do sistema, de modo a considerar irracional toda tentativa de romper com o status quo, sociedade essa que declara repetidamente o mantra "não há alternativa" (There is no alternative). (AQUINO, 2017, p. 291) 
Corpo do texto. Aos olhos da maior parte da classe dominada, qualquer força social de oposição que queira transformar a realidade posta é "irracional" (segundo os parâmetros de racionalidade do sistema), é imediatamente desacreditada e relegada ao esquecimento, sua contestação é inútil e suas reivindicações são "utópicas", isto é, não podem existir em lugar algum. Se a civilização existente parece "boa" e, dessa maneira, a "única" sociedade capaz de oferecer as comodidades que a torna confortável, sua recusa se torna impensável e até questionável: se a ordem social vigente é capaz de satisfazer as necessidades e interesses da maior parte dos indivíduos, por que transformá-la, por que destruí-la? "Diante de um crescente padrão de vida, a não-conformidade com o sistema parece ser socialmente inútil” (MARCUSE, 2015, p. 42).

Qualquer tendência de oposição às relações sociais vigentes que tente ou pretenda levantar alternativas capazes de iniciar a construção de novos modos de pensar e sentir a vida; novas formas de organizar as relações humanas é impedida de desenvolver-se ou lhe é permitido construir-se apenas dentro dos limites da sociedade estabelecida. Isso porque essa sociedade parece ser capaz de oferecer uma vida agradável e, por conseguinte, ela "pode, justamente, exigir a aceitação de seus princípios e instituições e reduzir a oposição à discussão e promoção de alternativas políticas dentro do status quo" (MARCUSE, 2015, p. 42).

Oposições como essas estão fadadas ao fracasso, pois não põem em cheque o modo de organização social atual, não visam a destruição da forma de vida existência presente, elas servem apenas para atrasar a revolução social e integrar ainda mais a classe trabalhadora à sociedade existente. Tal oposição é reformista, quer dizer, limita-se a lutar por reformas sociais que não tem interesse em superar as contradições da sociedade capitalista, sua aspiração é amenizar a exploração e dominação da classe oprimida. Portanto, uma oposição administrada, controlada pela classe dominante.

Não se pode negar a importância das reformas no que diz respeito à luta de classes, elas são necessárias para permitir que a classe dominada continue seguindo firme na luta contra a classe opressora, o problema é quando àquelas oposições limitam-se única e exclusivamente a lutar por reformas ${ }^{9}$. A crítica da oposição administrada não visa superar a sociedade capitalista, seus objetivos se reduzem a lutar para melhorar a vida da classe dominada dentro da realidade posta. Sua contestação contribui apenas para criar conformação ao estado de coisas predominante.

\footnotetext{
${ }^{9}$ Leandro Konder, no seu artigo Marcuse, Revolucionário afirma que Marcuse, ao ser "Entrevistado pela televisão alemã, num programa que o contrapunha a Karl Popper, fez questão de esclarecer que não tinha nada contra reformas úteis e viáveis, capazes de atenuar os sofrimentos dos homens" (KONDER, 1998, p. 24-25). Concordamos com a afirmação de Konder, mas queremos deixar claro que Marcuse não é um reformista, sua teoria crítica está sempre voltada para a destruição da sociedade capitalista.
} 
Os tipos de reforma que contribuem para a transformação da sociedade capitalista são as que escapam ao controle da classe dominante, são as que contribuem para fortalecer a resistência da classe oprimida na luta, são as que possibilitam o desenvolvimento da consciência revolucionária da classe dominada. Esses tipos de reformas "acabam preparando as condições nas quais a revolução se apresenta na 'ordem do dia”' (KONDER, 1998, p. 25). São essas reformas, cujo conteúdo prepara o terreno para a revolução que Marcuse apoia e incentiva como meios para a libertação.

Se os fins (libertação) não operam já nos meios (reformas), a oposição torna-se apenas uma tendência que coopera para fazer com que a classe dominada aceite as regras da sociedade estabelecida, ela colabora para tornar a submissão cada vez mais "voluntária" e para isolar as alternativas de transcendência ${ }^{10}$ dessa organização social. Assim, o capitalismo avançado é uma "'sociedade fechada', fechada porque disciplina e integra todas as dimensões da existência, privada ou pública" (MARCUSE, 1993, p. 7, tradução nossa). Tenta absorver e pôr na ordem social existente todo pensamento e comportamento que negue as formas autorizadas de pensar e se comportar.

Segundo Marcuse, "O poder do negativo [...] é dominado e se converte em um fator de coesão e de afirmação" (MARCUSE, 1993, p. 7), as forças de negação não conseguem perceber os motivos para se rebelarem contra a sociedade posta. As contradições se escondem atrás da fachada da ampliação do poder de compra e consumo. Assim, o pensamento crítico capaz de iniciar a ruptura dessa civilização está sendo conquistado pelo bem-estar social fornecido pela ordem social vigente.

Essa sociedade está conseguindo criar o pensamento e comportamento unidimensionais, quer dizer, o tipo de pensar que não consegue imaginar modos diferentes de organizar a vida, o tipo de comportamento que não consegue elaborar formas diferentes de sentir o mundo. Portanto, "A sociedade contemporânea parece ser capaz de conter a mudança social” (MARCUSE, 2015, p. 33), e esse poder de contenção impõe-se talvez como uma das suas principais conquistas.

\section{Novas formas de controle}

De acordo com Marcuse (1999, p. 73), no seu artigo Algumas implicações sociais da tecnologia moderna, "a tecnologia é vista como um processo social", isto significa que ela é parte integrante da sociedade e da vida dos seres humanos, quer dizer que é fundamental na organização da realidade existente. A tecnologia pode servir para melhorar e piorar a existência, reduzir e aumentar o tempo de trabalho

\footnotetext{
${ }^{10}$ Marcuse, n'O homem unidimensional, explica que 'Os termos 'transcendente' e 'transcendência' são usados no sentido totalmente empírico e crítico: eles designam tendências na teoria e na prática que, em uma sociedade dada, 'ultrapassam' o universo estabelecido do discurso e da ação na direção de suas alternativas histórias (possibilidades reais)” (MARCUSE, 2015, p. 33).
} 
exaustivo, tornar boa e ruim a vida dos homens e mulheres, libertar e dominar a classe oprimida. Na sociedade estabelecida, a técnica torna-se uma forma de vida que parece conter todas as alternativas de libertação.

A tecnologia, como modo de produção, como a totalidade dos instrumentos, dispositivos e invenções que caracterizam a era da máquina, é assim, ao mesmo tempo, uma forma de organizar e perpetuar (ou modificar) as relações sociais, uma manifestação do pensamento e dos padrões de comportamento dominantes, um instrumento de controle e dominação (MARCUSE, 1999, p. 73).

Presente em todas as dimensões da existência humana, a tecnologia impõe novos modos de pensar e se comportar, estes se manifestam através do modo de produção: da indústria, dos meios de comunicação, dos transportes, do trabalho, do lazer, do entretenimento etc., "O aparato produtivo e os bens e serviços que ele produz 'vendem' ou impõem o sistema social como um todo" (MARCUSE, 2015, p. 49). Na sociedade industrial avançada, o progresso técnico está sob o controle da classe dominante, dessa maneira, a tecnologia cria formas de vida com o objetivo de conquistar os interesses dessa classe, assim, a técnica desenvolve produtos com a intenção de impor o pensamento e comportamento da classe opressora. As mercadorias trazem consigo hábitos, costumes e atitudes que reconciliam a oposição, perpetuam a dominação e o modo de organização social existe.

O progresso técnico, estendido a um sistema de total dominação e coordenação, cria formas de vida (e de poder) que parecem reconciliar as forças que se opõem ao sistema e derrotar ou refutar todo protesto feito em nome das perspectivas históricas de libertação do trabalho árduo e da dominação (MARCUSE, 2015, p. 33).

A tecnologia, como processo social, cria uma "sociedade tecnológica” que organiza a vida das pessoas de maneira técnica, as relações sociais entre os indivíduos são mediadas quase exclusivamente pelo progresso técnico que impõe uma atitude tecnológica capaz de controlar o modo de viver das pessoas. Por exemplo, o diálogo entre os indivíduos é deslocado pela mensagem dos aparelhos celulares, há um distanciamento entre os seres humanos, um isolamento no qual a única relação existente é a do indivíduo com seu objeto. "As pessoas se reconhecem em suas mercadorias; encontram sua alma no seu automóvel, nos seus aparelhos hifi" (MARCUSE, 2015, p. 47), os indivíduos sentem prazer ao consumir os seus objetos.

Um adora o seu aparelho celular, o outro ama sua roupa e aquele venera o seu automóvel a ponto de viverem única e exclusivamente para os seus objetos, as pessoas parecem preocupar-se somente com a coisa amada, chegam mesmo ao ponto de pensar e se comportar tal como o objeto venerado. O ser humano se 
tornou parte da coisa, ele não existe sem ela, o seu automóvel lhe dá confiança, atrai as pessoas, lhe proporciona um determinado poder. $\mathrm{O}$ indivíduo parece não ter conhecimento de outra coisa a não ser que o assunto esteja relacionado ao seu objeto, o seu pensar, falar e se comportar estão ligados ao seu objeto.

Os seres humanos passam a pensar e se comportar de forma tecnológica, isto é, como uma máquina, um objeto, estes não pensam, não são autônomos, apenas fazem o que foram programados para fazer, e o conteúdo dessa programação é alcançar os objetivos da classe dominante. Nesse sentido, quando as pessoas pensam e se comportam de maneira técnica, elas estão pensando e agindo conforme os interesses da classe opressora, elas estão perpetuando a forma de civilização estabelecida. As pessoas são determinadas a pensar e agir de uma única maneira, para elas, não há outra forma de pensar e se comportar.

A tecnologia desenvolve um novo estilo de vida no qual o pensamento e comportamento da classe dominante e alguns dos seus valores: competição, eficiência e produtividade já estão prescritos nos produtos oferecidos pela sociedade prevalecente. As pessoas compram livros cujo conteúdo é uma receita para aprender a ser um bom funcionário, para aprender a fazer o seu trabalho da melhor maneira possível, os indivíduos estudam para aprender a ser um funcionário mais rentável para a empresa onde trabalha, ele compra um remédio para dar-lhe mais energia e, dessa maneira, ser mais produtivo. A forma de vida tecnológica invade todas as dimensões da existência e influencia na maneira de viver.

As pessoas tem acesso a TV por assinatura e podem baixar uma série de filmes e seriados através dos vários sites disponíveis na Internet, mas essas tecnologias trazem consigo os hábitos, os costumes e as atitudes da classe opressora. Ademais, essas técnicas isolam os indivíduos dentro de suas casas, afastam os seres humanos uns dos outros. Esse é o estilo de vida tecnológico, um modo de viver controlado, administrado e não-livre. Segundo Marcuse,

Os produtos doutrinam e manipulam; eles promovem uma falsa consciência que é imune a sua falsidade. E como esses produtos benéficos tornam-se disponíveis a mais indivíduos em mais classes sociais, a doutrinação que eles levam a cabo deixa de ser publicidade; torna-se um estilo de vida. É um bom estilo de vida muito melhor que antes - e enquanto um bom estilo de vida, ele age contra a mudança qualitativa. (2015, p. 49-5o)

É um estilo de vida confortável, que traz a esperança de uma vida melhor no interior da sociedade capitalista, a vida boa parece capaz de alcançar um número cada vez maior de pessoas e, para adquirir esse tipo de vida os indivíduos não necessitam fazer uma revolução, não precisam pôr em risco suas próprias vidas e de suas famílias. O elevado padrão de vida torna a classe oprimida conformada, ela tem medo de perder os confortos conquistados, a própria forma de vida tecnológica 
torna-se um poder que impede e reduz a necessidade de uma subversão total da sociedade capitalista. "Sob esse aspecto, a tecnologia e o conforto tornaram-se impedimentos de libertação (...)" (SILVA, 2015, p. 149-50).

A tecnologia, compreendida como modo de produção, instrumentos e invenções, entendida como manifestação do pensamento e comportamento da classe opressora, compreendida como forma de vida estabelecida, transforma-se em instrumento de dominação. Com o desenvolvimento da sociedade estabelecida, a técnica foi sendo cada vez mais aperfeiçoada, o seu aprimoramento criou novas formas de controle, formas diferentes de dominação. Esta não se dá mais essencialmente pela violência da polícia, mas pelo fornecimento de um padrão elevado de vida.

Se nos períodos anteriores da sociedade capitalista a dominação da classe trabalhadora era quase totalmente exercida pela violência da polícia, guarda nacional e exército, agora, com o novo estágio do sistema capitalista, esse tipo de controle só é imposto caso os benefícios oferecidos pela tecnologia não sejam suficientes para barrar a revolta. A violência brutal das autoridades de proteção do establishment ainda existe e seus equipamentos de repressão estão bem mais aperfeiçoados. Se mesmo com todo o conforto, àquela classe insiste em contestar e se mostra insatisfeita, a brutalidade das forças de defesa é acionada para pôr a disciplina da realidade presente.

As capacidades (intelectuais e materiais) da sociedade
contemporânea são incomensuravelmente maiores que jamais
foram - o que significa que o escopo da dominação da sociedade
sobre o indivíduo é incomensuravelmente maior do que antes.
Nossa sociedade se distingue pela conquista das forças sociais
dissidentes mais precisamente pela Tecnologia do que pelo Terror,
sobre a dupla base de uma eficiência esmagadora e de um crescente
padrão de vida (MARCUSE, 2015, p. 31-32).

A tecnologia não contribui somente com a dominação em escala nacional, mas também em âmbito internacional, isso se manifesta quando ajuda aprimorar os meios que destroem a natureza e as pessoas; quando produz e reproduz as intervenções militares, a guerra, etc., em proveito da opressão. Com a ajuda da técnica, a indústria bélica produz armas com potencial para mutilar, bombas capazes de incendiar e destruir em massa, mísseis com precisão de destruição a longa distância. Com a ajuda da tecnologia, os países desenvolvidos submetem os países subdesenvolvidos à sua política de dominação neocolonial.

Para Marcuse, a técnica não pode ser compreendida por si mesma, isolada do mundo, desvinculada das relações sociais;segundo o filósofo, o progresso técnico é sempre entendido como uma relação social, assim, no capitalismo tardio ele está sob a direção da classe dominante. No entanto, se a tecnologia passasse ao controle 
da classe dominada, deixaria de ser meio de dominação e passaria a ser instrumento de libertação, os objetivos que buscaria seriam outros, o progresso técnico passaria a ser direcionado para conquistar os interesses da classe dominada. Haveria uma transformação radical da sociedade vigente, surgiram novas relações sociais.

De acordo com Marcuse (1977, p. 34), "a liberdade depende pois largamente do progresso técnico, do avanço da ciência”. Sob o controle da classe oprimida, a tecnologia poderia ser usada para satisfazer as necessidades básicas de alimentação, vestuário e moradia, quer dizer, poderia ser usada para extinguir a miséria na qual está submetida uma quantidade cada vez maior de pessoas. A técnica poderia ser utilizada para reduzir ao mínimo o tempo de trabalho exaustivo e, assim, liberar os homens e mulheres para que pudessem desenvolver novas relações sociais.

A produtividade para o lucro não seria mais um objetivo, um valor social; o modo de produção seria alterado. Conforme comenta Pisani (2006, p. 607), "em Marcuse toda transformação no sentido da emancipação deve pressupor uma transformação na base técnica em que se assenta a produção na sociedade". Com essa alteração, a satisfação das necessidades vitais seria prioridade, a produção de produtos supérfluos que destrói a natureza seria reduzida, o modo de produção seria organizado e orientado para a produção de objetos que melhorassem qualitativamente a vida da natureza e dos seres humanos. A vida não seria mais destruída pela fumaça dos automóveis, pelos rótulos e embalagens descartáveis dos artigos de luxo.

Com isso,Marcuse não propõe o retorno a um estágio menos desenvolvido da sociedade, "ao contrário, considera que só atingido um determinado nível de avanço técnico e científico o real poderá ser racional” (KANGUSSU, 2008, p. 12). Na sociedade existente, a ciência e a tecnologia já alcançaram esse nível, entretanto, estão presas aos interesses da classe dominante e por isso são impedidas de criar relações sociais que possibilitem aos indivíduos "viver, viver bem e viver melhor". Somente uma revolução social exercida pela classe dominada pode libertar a tecnologia de suas amarras.

Não mais restrita aos interesses da classe dominante, a tecnologia pode auxiliar a classe dominada a destruir os valores vigentes da classe opressora: competição, eficiência, produtividade, e construir novos valores, tais como, união, solidariedade e cooperação entre os seres humanos. Em vez de produzir guerra, o progresso técnico promoveria a paz, a brutalidade seria substituída pela delicadeza e a superexploração da natureza daria espaço à utilização razoável dos recursos naturais. É nesse sentido que a técnica, sob o controle da classe dominada, se tornaria veículo de libertação.

As pessoas não seriam mais controladas pela tecnologia, suas vidas deixariam de ser administrada, tanto a dimensão pública quanto a dimensão privada da 
existência dos seres humanos não seria mais afetada pela manipulação imposta pelos meios de comunicação, o pensamento e comportamento dos indivíduos não seriam mais doutrinados. Os indivíduos seriam autônomos, donos de suas próprias vidas, "O espaço particular, a dimensão da negação e da individualidade" (KELLNER, 2015, p. 21) seria reconstruído. Haveria o retorno do pensar e agir crítico, negativo e contestador das relações sociais de dominação.

A sociedade industrial avançada está se aproximando do estágio em que o progresso contínuo exigiria a subversão radical da direção e da organização predominantes do progresso. Esse estágio seria alcançado quando a produção material (incluindo os serviços essenciais) se tornar automatizada até o ponto em que todas as necessidades vitais possam ser satisfeitas enquanto o tempo necessário de trabalho é reduzido a um tempo mínimo (MARCUSE, 2015, p. 53).

A tecnologia tornar-se-ia um veículo de libertação da classe oprimida quando esta levar a cabo uma revolução que possa transformar a organização vigente do modo de produção estabelecido. Sob o controle da classe oprimida, o progresso técnico seria dirigido para a automação total da produção, com isso, as necessidades básicas seriam satisfeitas, o tempo de trabalho alienado seria reduzido ao mínimo. Com a redução do tempo de labuta, os indivíduos seriam liberados das atividades exaustivas e disporiam de tempo livre para criar novas relações sociais qualitativamente diferentes.

\section{Racionalidade tecnológica}

Com o aprimoramento da tecnologia, desenvolveu-se ao mesmo tempo uma racionalidade tecnológica, segundo Oliveira (2015, p. 122), "a tecnologia se tornou o meio pelo qual os indivíduos se relacionam, à natureza e a seu próprio meio ambiente, e ela desenvolveu sua própria racionalidade”. Essa racionalidade é um modo de pensar que estar direcionado para a conquista de determinados objetivos, e estes interesses não são as aspirações de todos os indivíduos. A racionalidade tecnológica é um instrumento de dominação dirigido para impor os fins determinados pela classe dominante.

Segundo Marcuse (1999, p. 77), “esta racionalidade estabelece padrões de julgamento e fomenta atitudes que predispõem os homens a aceitar e introjetar os ditames do aparato". Este aparato", isto é, o modo de produção capitalista, a tecnologia, cria formas de vida nas quais o pensamento e comportamento crítico das pessoas transforma-se em pensar e agir tecnológicos. A técnica invade as dimensões pública e privada da existência humana, os interesses da classe dominante são

\footnotetext{
${ }^{11}$ Marcuse, no artigo algumas implicações sociais da tecnologia moderna,explica que "O termo 'aparato' designa as instituições, dispositivos e organizações da indústria em sua situação social dominante" (MARCUSE, 1999, p. 77).
} 
impostos através da ampliação de um padrão de vida elevado. Dessa maneira, desenvolve-se um conformismo com estado de coisas estabelecido, a razão crítica dos indivíduos é reduzida e se transforma em racionalidade acrítica, tecnológica.

A racionalidade técnica "é o equivalente da razão instrumental, trata-se do cálculo de custo-benefício, visando eficiência, produtividade e lucro" (OLIVEIRA, 2010, p. 4), uma das características desse modo de pensar é que ele dirige o seu saber instrumental com a finalidade de desenvolver os meios que possibilitem a obtenção de uma maior quantidade de lucro com uma menor quantidade de gastos. A razão tecnológica não se importa com os fins para os quais serve, não cabe a ela questionar sobre os objetivos estabelecidos, sua tarefa consiste em obedecer às normas impostas. Para essa racionalidade não interessa o "por que" fazer, mas apenas o "saber" fazer.

O pensamento tecnológico é a racionalidade da dominação, é a razão treinada para criar e aperfeiçoar as formas de controle social. Ela é preparada para perpetuar o modo de vida vigente, é uma racionalidade a serviço da classe opressora, incapaz de pensar e questionar sobre os benefícios e malefícios de sua própria racionalidade. A razão tecnológica compreende o mundo e as pessoas como objetos úteis ou inúteis, para ela os indivíduos são úteis na medida em que são capazes de gerar lucro à classe dominante, e são inúteis quando recusam ser meros produtores de lucro.

Dessa forma, os seres humanos são úteis quando direcionam suas inteligências para o desenvolvimento de estratégias e criação de aparelhos que possibilitem a produção de uma maior quantidade de artigos em menos tempo e com menos custos; as pessoas têm utilidade quando dirigem suas vidas para o trabalho alienado e para o consumo de seus produtos. "A racionalidade técnica (ou tecnológica) domina os indivíduos prendendo-os no círculo vicioso de aquisição de mercadorias ao mesmo tempo em que sua identidade é dissolvida por esse processo" (OLIVEIRA, 2012, p. 165).

Segundo Kellner (2015, p. 165), “o desenvolvimento da indústria moderna e da racionalidade tecnológica, [...] minou as bases da racionalidade individual”. A razão tecnológica está conseguindo reduzir os padrões e valores críticos da racionalidade individual $^{12}$, quer dizer, está reduzindo a capacidade dos indivíduos de compreender qual a forma de organização social que pode desenvolver suas potencialidades. A razão individual está perdendo o poder de construir seu próprio destino, o poder de discordar e negar da ordem social estabelecida que restringe o aprimoramento das capacidades e habilidades humanas.

\footnotetext{
12 "A racionalidade individualista nasceu como uma atitude crítica e de oposição que derivava a liberdade de ação da liberdade irrestrita de pensamento e consciência e media todos os padrões e relações sociais pelo interesse próprio racional do indivíduo" (MARCUSE, 1999, p. 97).
} 
O sujeito que dispunha da racionalidade individual era o indivíduo crítico que não se conformava com a realidade social desprovida de meios para $o$ desenvolvimento de suas potencialidades, a racionalidade individual era a dimensão da razão capaz de visualizar as possibilidades de transcender o status quo que limitasse o aperfeiçoamento das capacidades dos homens e mulheres. Para Marcuse, o indivíduo que dispunha daquela racionalidade era

[...] o sujeito de certos padrões e valores fundamentais que nenhuma autoridade externa deveria desrespeitar. Esses padrões e valores diziam respeito às formas de vida, tanto social como pessoal, que se mostravam mais adequadas ao desenvolvimento total das faculdades e habilidades do homem (MARCUSE, 1999, p. 75).

O sujeito que dispunha da racionalidade individual era capaz de compreender quando a ordem social existente não podia satisfazer o seu interesse próprio racional $^{13}$, estava sempre pronto para contestar os padrões e valores vigentes que impediam uma vida qualitativamente melhor para todas as pessoas. Ele estava preparado para criticar as normas impostas pela classe dominante, disposto a rejeitar as leis estabelecidas que reduzissem as condições de uma existência racional. Essas eram suas formas de resistir à dominação, de lutar contra um estado de coisas opressor.

O desenvolvimento da racionalidade tecnológica criou um modo específico de organizar a vida, uma forma de existência que contém regras e normas cuja finalidade é justificar as relações sociais prevalecentes na sociedade capitalista. Dessa maneira, a razão técnica inculca na cabeça dos indivíduos os falsos benefícios do modo de produção e a importância de aprimorá-lo para ampliar a entrega de mercadorias.

Como as leis e os mecanismos da racionalidade tecnológica estão difundidos por toda a sociedade, desenvolvem um conjunto de valores de verdade próprios que serve bem ao funcionamento do aparato - e para isso apenas (MARCUSE, 1999, p. 84).

Presente tanto na dimensão da vida privada quanto na dimensão da existência pública, a racionalidade tecnológica influência o modo de pensar e agir das pessoas no trabalho alienado, no tempo de lazer, nas relações familiares e não-familiares, essa racionalidade determina como os indivíduos devem pensar e se comportar em cada momento de suas vidas. Assim, durante o trabalho exaustivo os indivíduos não pensam sobre o tipo de produto que estão auxiliando a produzir, não pensam acerca de sua atividade: se lhe proporciona prazer ou se atrofia sua criatividade.

\footnotetext{
${ }^{13}$ Para Marcuse (1999, p. 75), o "interesse próprio racional" não coincide com "interesse próprio imediato do indivíduo". O primeiro deriva do pensamento autônomo, da consciência. O último depende "dos padrões e demandas da ordem social dominante", é instituído "por autoridades externas".
} 
As pessoas gastam o seu tempo de lazer usufruindo do entretenimento, da programação e dos produtos estabelecidos, cuja tarefa consiste em fazer os indivíduos relaxarem, imaginarem e sentirem que também podem ter uma vida igual aos de seus patrões, das celebridades, etc., mesmo que por poucas horas. De acordo com Marcuse (2015, p. 47), "se o trabalhador e seu chefe se divertem com o mesmo programa de televisão e visitam os mesmos lugares de lazer e descanso”, isso apenas indica que a racionalidade tecnológica está conseguindo impor à classe trabalhadora as necessidades e satisfações que perpetuam o establishment.

Na sociedade industrial avançada, verifica-se uma expansão cada vez maior da racionalidade tecnológica, o seu modo de organizar as relações sociais impõe hábitos e costumes que ajudam essa sociedade a aumentar o seu poder opressivo sobre a classe oprimida. A razão tecnológica cria as normas e leis necessárias para manter a classe dominada na condição de classe oprimida, ela cria formas de vida nas quais as classes antagônicas estão unidas para garantir um objetivo comum: a perpetuação do status quo. A razão técnica está em estreita relação com a dominação política.

Segundo Marcuse, a racionalidade tecnológica tem, no capitalismo, um vínculo indissolúvel com a dominação política ou, em outros termos, a ciência e a técnica estão inseridas num "projeto" que serve aos interesses do capital, elas não são neutras (LOUREIRO, 2005, p. 14).

Enfim, a racionalidade tecnológica está conseguindo reduzir a racionalidade crítica capaz de compreender novas formas de organização social, àquela razão impede o exercício do modo de pensar negativo, que rejeita uma realidade provida de instrumentos restritivos do desenvolvimento das potencialidades humanas. A "racionalidade tecnológica [...] molda a atitude e os interesses daqueles que dependem dela, de modo que todos os objetivos e valores transcendentes são eliminados” (MARCUSE, 1999, p. 87). É assim que a razão tecnológica reduz as alternativas de superação da sociedade capitalista.

Organizada e direcionada para conquistar os fins impostos pela classe burguesa, a racionalidade tecnológica se restringe a criar os meios para o desenvolvimento de um projeto de sociabilidade que possa manter um ganho de lucro sempre maior e uma posição de privilégio para um setor minoritário da sociedade. A serviço da dominação, a razão técnica torna-se instrumento de opressão que visa conquistar e perpetuar os valores da classe dominante: competição, eficiência, produtividade e lucro. Essas são algumas das características da racionalidade tecnológica.

Entretanto, não mais restrita a criar os meios para conquistar os interesses da classe opressora, a razão técnica deixaria de ser instrumento de dominação e tornarse-ia instrumento de libertação, nesse sentido a racionalidade tecnológica seria 
organizada e direcionada para criar novas formas organização social. O objetivo da razão tecnológica seria contribuir na transformação das relações sociais, os valores existentes seriam destruídos e outros valores qualitativamente diferentes seriam reconstruídos. Solidariedade, cooperação, união e confraternização universal entre os seres humanos seriam os novos valores.

A racionalidade técnica teria a tarefa de auxiliar o desenvolvimento da criatividade das pessoas no que diz respeito à invenção de novas formas de produzir e consumir, de se relacionar com a vida humana e natural.

\section{Considerações finais}

A racionalidade tecnológica criou uma sociedade e um homem unidimensional, ela desenvolveu um "mundo técnico unidimensional onde a 'pura instrumentalidade' e 'eficácia' de organizar meios e fins dentro de um universo preestabelecido é o 'princípio comum de pensamento e ação"' (KELLNER, 2015, p. 20). Nesse mundo de uma única dimensão, prevalece um único modo de pensamento e comportamento, as formas de pensar e agir alternativos parecem não existir. Os modos de pensamento e ação diferentes são impedidos de penetrar nessa sociedade unidimensional.

Nessa sociedade, o pensar e agir que recusa seguir as regras e leis vigentes é visto como um inimigo que deve ser combatido, pois esse adversário percebe que o objetivo da racionalidade técnica que organiza a realidade existente é gerar lucro e posição privilegiada para a classe dominante. A razão tecnológica, através de suas formas de dominação - fornecimento de artigos de luxo, conforto, padrão de vida elevado - deu os passos decisivos para a construção do pensamento e comportamento unidimensional. $\mathrm{O}$ fornecimento de produtos que tornam a vida confortável, boa e agradável, ao mesmo tempo que gera lucro e posição privilegiada, faz surgir

[...] um padrão de pensamento e comportamento unidimensional, no qual as ideias, as aspirações e objetivos que, por seu conteúdo, transcendem o universo estabelecido do discurso e da ação, são ou repelidos ou reduzidos aos termos desse universo. Eles são redefinidos pela racionalidade do sistema dado e de sua extensão quantitativa (MARCUSE, 2015, p. 49-5o, grifos do autor).

A racionalidade tecnológica organiza a sociedade de maneira unidimensional, ou seja, a realidade de uma única dimensão está preparada para impor o conformismo a todos os indivíduos inconformados, ela está pronta para desacreditar qualquer indício de ideias críticas, ordenada para repelir as alternativas de transcendência do status quo. Dessa maneira, o pensamento alternativo, que compreende novas formas de organizar a vida é impedido de penetrar no pensamento unidimensional. $\mathrm{O}$ pensamento crítico, cuja função é recusar todas as 
formas de dominação, é paralisado, não consegue ser absolvido pelo sujeito revolucionário.

Sem o pensamento crítico, o sujeito revolucionário torna-se sujeito conformado, aceita as regras e ordens estabelecidas porque essas normas são as mesmas que lhe proporcionam uma vida confortável, a necessidade da transformação social é reduzida na medida em que as pessoas tem medo de perder os benefícios conferidos por essa sociedade. Integrados a essa forma de existência, os indivíduos não conseguem perceber as contradições da sociedade unidimensional e nem visualizar as possibilidades de superação dessa realidade.

A ordem unidimensional cria um homem unidimensional, um ser humano que só ver o que está diante de seus olhos, ele não consegue enxergar além do fato, o que está presente lhe aparece como imutável, a organização social dada parece a única possível e uma sociedade diferente torna-se imaginável. O homem unidimensional é impossibilitado de reconhecer seus inimigos e lutar contra as injustiças perpetradas por eles, pois a própria sociedade unidimensional bloqueia a efetivação da revolta. Assim, a realidade existente torna-se "uma ordem unidimensional capaz de absorver para si todas as suas oposições" (CARNEIRO, 2012, p. 192).

O homem unidimensional não é capaz de reconhecer suas próprias necessidades e interesses, estes são confundidos com as necessidades e aspirações da classe dominante, que são interesses predominantes na sociedade unidimensional, aqui acontece o que Marcuse denomina de unificação dos opostos. A reconciliação das classes antagônicas reduz o pensamento revolucionário da classe dominada, ela está no interior de uma ordem social em que todas as pessoas estão unidas com objetivo de conquistar o bem comum. A convergência dos opostos reduz a concepção de que "A história de todas as sociedades até hoje existentes é a história da luta de classes" (MARX; ENGELS, 2010, p. 40).

Assim, a luta de classes, que é o motor do desenvolvimento social e a principal contradição a ser resolvida, é desacreditada e cai no esquecimento, prevalece "uma situação em que não há classes ou grupos revolucionários para militar pela mudança social e na qual os indivíduos estão integrados à sociedade existente" (KELLNER, 2015, p. 22-23). A sociedade unidimensional está conseguindo realizar o que os estágios anteriores da sociedade capitalista não conseguiram fazer: a construção de uma sociedade sem oposição. Dessa forma, a sociedade unidimensional reduz cada vez mais as possibilidades de emancipação.

Com uma sociedade e um homem cada vez mais unidimensionais, as alternativas de libertação só podem surgir como tendências capazes de romper a consciência e o comportamento administrados da classe trabalhadora, essas tendências de ruptura da ordem vigente podem contribuir com a superação da sociedade e do homem unidimensional. Uma dessas tendências são os pequenos 
grupos existentes no interior da sociedade estabelecida que, em virtude da sua consciência e comportamento revolucionário podem reativar o pensamento e práxis transformadora da classe trabalhadora. Esses pequenos grupos aparecem como forças de desintegração, tendências que podem ajudar a classe trabalhadora a perceber as contradições da sociedade unidimensional e destruir a forma de vida existente. Enfim, essas tendências podem estimular o ressurgimento do pensamento crítico, multidimensional, capaz de pensar e criar uma nova sociedade um novo homem.

\section{Referências}

AQUINO, J. K. S. “Diagnóstico realista ou pessimista? Aspectos introdutórios do capitalismo tardio no 'O homem unidimensional' de Herbert Marcuse”. Revista Reflexões. Fortaleza, v. 6, n. 10, 2017, pp. 290-302. Disponível em: <http://revistareflexoes.com.br/wpcontent/uploads/2017/07/20.1.1-Jonh-290-a-302.pdf>. Acesso em: 02 ago. 2017.

CARNEIRO, S. R. G. Resenha. Collected Papersof Herbert Marcuse (Philosophy, Psychoanalysis and Emancipation) Cadernos de Ética e Filosofia Política. São Paulo: n. 2o, p. 185-193, 2012.

KANGUSSU, I. Introdução. In: Leis da liberdade: a relação entre estética e política na obra de Herbert Marcuse.São Paulo: Loyola, 2008.

KELLNER, D. Introdução à $2^{a}$ edição. In: MARCUSE, Herbert. O homem unidimensional: estudos da ideologia da sociedade industrial avançada. Tradução de Robespierre de Oliveira, Deborah Christina Antunes e Rafael Cordeiro Silva. São Paulo: Edipro, 2015.

KONDER, L. "Marcuse, Revolucionário”. PHYSIS: Rev. Saúde Coletiva.Rio de Janeiro, v. 8, n. 1, pp. 15-28, 1998.

LOUREIRO, I. "Herbert Marcuse - anticapitalismo e emancipação".Trans/Form/Ação. São Paulo, v. 28, n. 2, 2005, pp. 7-20. Disponível em:

<http://www.scielo.br/pdf/trans/v28n2/29411.pdf>. Acesso em: 23 jul. 2017.

. "Herbert Marcuse: cem anos". Crítica Marxista.São Paulo, n. 7, 1998. Disponível em: <http://www.ifch.unicamp.br/criticamarxista/arquivos_biblioteca/nota12Nota2.pdf>. Acesso em: 03 mar. 2018.

MARCUSE, H. O homem unidimensional:estudos da ideologia da sociedade industrial avançada. Tradução de Robespierre de Oliveira, Deborah Christina Antunes e Rafael Cordeiro Silva. São Paulo: Edipro, 2015.

Algumas implicações sociais da tecnologia moderna. In: Tecnologia, guerra e fascismo. Tradução de Maria Cristina Vidal Borba. São Paulo: Fundação Editora da UNESP, 1999.

. Prefacio a la edición francesa. In: . El hombre unidimensional: ensayo sobre la ideología de la sociedad industrial avanzada. Traducción del Antonio Elorza. Barcelona: Planeta-De Agostini, 1993.

. Um ensaio sobre a libertação.Tradução de Maria Ondina Braga. Lisboa: Livraria Bertrand, 1977.

MARX, K; ENGELS, F. Manifesto Comunista.Tradução de Álvaro Pina e Ivana Jinkings. 1. ed. rev. São Paulo: Boitempo, 2010. 
OLIVEIRA, R. de. "Catástrofe da libertação: revoltas e contrarrevolução”. In: Revista Artefilosofia. Ouro Preto, v. 10, n. 18, 2015, pp. 111-129. Disponível em: <http://www.periodicos.ufop.br/pp/index.php/raf/article/view/491/447>. Acesso em: 23 jul. 2017.

. "Marcuse entre filosofia e marxismo: da filosofia concreta à teoria crítica". In: $O$ papel da filosofia na teoria crítica de Herbert Marcuse. São Paulo: Editora Unesp, 2012.

. "Crítica cultural e sociedade unidimensional". Artefilosofia. Ouro Preto, v. 6, n. 11, 2011, pp. 158-169. Disponível em:

<http://www.periodicos.ufop.br/pp/index.php/raf/article/view/604/56o >. Acesso em: 23 jul. 2017.

As afinidades eletivas: Marcuse e Benjamin. In: Seminário Internacional Políticas de la Memoria - Recordando a Walter Benjamin: Justicia, História y Verdad. Escrituras de la Memoria. 3, 2010, Buenos Aires, Anais, Buenos Aires, p. 1-12.

PISANI, M. M. A "máquina” como instrumento de controle na sociedade tecnológica Herbert Marcuse crítico da tecnologia. In: Congresso Internacional Indústria Cultural Hoje. 1, 2006, Piracicaba, Anais, Piracicaba, p. 1-14.

SILVA, R. C. “Traduzir Marcuse: O homem unidimensional”. Ouro Preto, v. 10 n. 18, pp. 146150, 2015. Disponível em:

<http://www.periodicos.ufop.br/pp/index.php/raf/article/view/493/449>. Acesso em: 23 jul. 2017.

. "Tecnologia e progresso: dois pontos de vista da teoria crítica". In: Pensando Revista de Filosofia. Piauí, v. 4, n. 7, 2013, pp. 55-69. Disponível em:

<http://www.ojs.ufpi.br/index.php/pensando/article/view/1447/1072>. Acesso em: 07 mar. 2017.

Submissão: 01. 04. 2018 / Aceite: 02. 06. 2018. 